\title{
Bioimaging of Nucleolin Aptamer-Containing 5-(N-benzylcarboxyamide)-2'-deoxyuridine More Capable of Specific Binding to Targets in Cancer Cells
}

\author{
Kyue Yim Lee, ${ }^{1}$ Hyungu Kang, ${ }^{2}$ Sung Ho Ryu, ${ }^{2}$ Dong Soo Lee, ${ }^{3}$ \\ Jung Hwan Lee, ${ }^{2}$ and Soonhag Kim ${ }^{1}$ \\ ${ }^{1}$ Laboratory of Molecular Imaging, Department of Applied BioScience, CHA Stem Cell Institute, CHA University, \\ Seoul 135-081, South Korea \\ ${ }^{2}$ Aptamer Initiative, POSTECH Biotech Center, Pohang University of Science and Technology, Pohang, \\ Kyungbuk 790-784, South Korea \\ ${ }^{3}$ Department of Nuclear Medicine, Seoul National University College of Medicine, Seoul 110-744, South Korea \\ Correspondence should be addressed to Soonhag Kim, kimsoonhag@empal.com
}

Received 11 June 2009; Revised 8 September 2009; Accepted 19 November 2009

Academic Editor: Daehee Kang

Copyright () 2010 Kyue Yim Lee et al. This is an open access article distributed under the Creative Commons Attribution License, which permits unrestricted use, distribution, and reproduction in any medium, provided the original work is properly cited.

Chemically modified nucleotides have been developed and applied into SELEX procedure to find a novel type of aptamers to fit with targets of interest. In this study, we directly performed chemical modification of 5-( $N$-benzylcarboxyamide)-2' -deoxyuridine (called 5-BzdU) in the AS1411 aptamer, which binds to the nucleolin protein expressed in cancer cells. Forty-seven compounds of AS1411-containing Cy3-labeled 5-BzdU (called Cy3-(5-BzdU)-modified-AS1411) were synthesized by randomly substituting thymidines one to twelve in AS1411 with Cy3-labeled 5-BzdU. Both statistically quantified fluorescence measurements and confocal imaging analysis demonstrated at least three potential compounds of interest: number 12, 29 and 41 that significantly increased the targeting affinity to cancer cells but no significant activity from normal healthy cells. These results suggest that the position and number of substituents in AS1411 are critical parameters to improve the aptamer function. In this study, we demonstrated that chemical modification of the existing aptamers enhanced the binding and targeting affinity to targets of interest without additional SELEX procedures.

\section{Introduction}

Aptamers are 60 80 mers composed of synthetic ribonucleic acid (RNA) or deoxyribonucleic acid (DNA) oligonucleotides that have been identified by a process called systematic evolution of ligands by exponential enrichment (SELEX); this process is based on high affinity and specific molecular fit with targets of interest [1-3]. Aptamer have recently been used as the preferred compounds for the diagnosis and treatment of cancers as imaging target agents, rather than monoclonal antibodies. They have the following characteristics that make them more desirable: they are inexpensive, efficient, and rapidly produced, highly stable during long-term storage, versatile molecules that can be easily modified with imaging probes, their small size (8$15 \mathrm{kDa}$ ) results in a low immune risk and better penetration into target tissues in vivo, and they have a high affinity to molecular target. There are a large number of aptamers that target cancer-related proteins including Wilim's tumor protein 1, transcription factor 1, human epidermal growth factor receptor 3 , prostate-specific membrane antigene, tenascin$\mathrm{C}$, nucleolin, pigpen, and vascular endothelial growth factor; all of these proteins have been developed for targeting and imaging cancers [4-11].

Chemical modifications of the ribose backbone of aptamer nucleotides, using 2 ' -amino or-fluoro pyrimidines, have been performed in situ and in vitro with the existing aptamers that cause resistance to nucleases and improve transfer across membranes or specific binding to a target of interest; however, this frequently resulted in the alteration of the structure of the aptamers and results in the loss of the properties the aptamer $[12,13]$. Therefore, recent chemical modifications including 2'-O-methyl nucleotides, boranophophate 
internucleotide linkage, and 4 '-thio-uridine or hydrophobic groups like benzyl, pentynyl, napthyl, or tryptophan of $2^{\prime}$ deoxyuridines modified at position 5 have been directly added to the SELEX procedure. The results have shown stable and/or high affinity aptamers with electrostatic and hydrophobic interactions of nucleic acids and their targets [14-18]. These findings imply that the aptamers, identified to date, might be less valuable or that the currently known aptamers and their targets of interest should undergo additional SELEX with the chemically modified nucleotides. However, post-SELEX chemical modifications might be useful by directly ameliorating the physical stability and binding affinity of the existing aptamers to their targets.

In this study, to improve the target affinity of aptamers, one of the existing aptamers, nucleolin aptamer (AS1411), was selected for investigation. AS1411 is a guanine (G)rich oligonucleotide (GRO) aptamer in the G-quadruplex structure that has been shown to exhibit antiproliferative effects by specifically binding to the nucleolin transmembrane protein in cancer cells $[7,19]$. Chemical modification of the pyrimidine base backbone of the AS1411 nucleotides was performed to increase the binding affinity to targets. One to 12 AS1411 thymidines were randomly substituted with 5(N-benzylcarboxyamide)-2' -deoxyuridine (designated as 5BzdU) labeled with Cy3. The targeting affinity of the Cy3 labeled AS1411 containing 5-BzdU (designated as Cy3-(5BzdU)-modified-AS1411) was quantified; in addition, imaging of the C6 (rat glioma cell line) and HeLa (human cervical cancer cells) cells in the cancer cell line was performed.

\section{Material and Methods}

2.1. Synthesis of Cy3-(5-BzdU)-Modified AS1411. Cy3AS1411 and Cy3-(5-BzdU)-modified AS1411 was synthesized using a Mermade 12 DNA synthesizer (BioAutomation Manufacturing, Irving, TX, USA) by standard solid phase phosphoramidite chemistry. 5-( $N$-benzylcarboxyamide)- $2^{\prime}$ deoxyuridine-phosphoramidite was provided by Samchully Pharmaceutical (Seoul, South Korea). All oligonucleotide synthesis procedures were performed in house. The synthetic oligonucleotides were purified using a Poros $\mathrm{HQ}$ anion exchange column (PerSeptive Biosystems, Framingham, MA, USA) or polyacrylamide gel electrophoresis (PAGE) system. Anion exchange was performed by gradient elution with $1 \mathrm{M}$ $\mathrm{NaCl}$ solution. The purified aptamers were precipitated by ethanol and desalted using a Centricon (Millipore Bedford, MA, USA). Finally, the desalted aptamers were resuspended in water or phosphate buffered saline and sterilized by filtration through a $0.2 \mu \mathrm{m}$ syringe filter. The molecular weight and purity of each aptamer was evaluated by Q-TRAP 2000 ESI-MS spectroscopy (Applied Biosystems, Foster city, CA, USA) and P/ACE 2000 capillary gel electrophoresis (Beckman coulter. Fullerton, CA, USA).

2.2. Oligonucleotide Synthesis, Purification, and Characterization. All oligonucleotides were synthesized on functionalized controlled pore glass (CPG) on an automated solid phase DNA synthesizer using $0.067 \mathrm{M}$ solution of the 5( $N$-benzylcarboxyamide)-2'-deoxyuridine-amidite in anhydrous acetonitrile. For incorporation of $\mathrm{dA}, \mathrm{dG}, \mathrm{dC}$, and $\mathrm{dT}$ residues standard phosphoramidites with excyclic amino groups protected by benzoyl group (for $\mathrm{dA}$ and $\mathrm{dC}$ ) and isobutyryl groups (for $\mathrm{G}$ ) were used. For incorporation of 5-( $N$-benzylcarboxyamide)-2' -deoxyuridine-amidite, phosphoramidite solution was delivered in two portions, each followed by a 5-minute coupling wait time. Oxidation of the internucleotide phosphate to phosphate was carried out using an oxidizer (tetrahydrofuran (THF), pyridine, $0.02 \mathrm{M}$ iodine and water) with waiting time. All other steps in the protocol supplied by the manufacturer were used without modification. The coupling efficiencies were $>97 \%$. After completion of the synthesis, the next step was treatment with the cleavage solution $(t$-butylamine : methanol: water, $1: 1$ : 2) at $70^{\circ} \mathrm{C}$ for 5 hours to hydrolyze the ester linking the DNA to the support and removal of the protective groups from the purine and pyrimidine bases; this was followed by freezing, filtration, and speed-vac evaporation to dryness.

Crude oligonucleotides were purified by high performance liquid chromatography (AKTA basic HPLC, XBridge OST C18 $10 \times 50 \mathrm{~mm}, \mathrm{~A}=100 \mathrm{mM}$ buffer triethylammoniumbiocarbonate (TEAB), $\mathrm{pH}=7, \mathrm{~B}=$ acetonitrile, $8 \%$ to $40 \% \mathrm{~B}$ in 20 minutes, flow $5 \mathrm{~mL} \mathrm{~min}^{-1}$, at $65^{\circ} \mathrm{C}$, $1=254$ and $290 \mathrm{~nm}$ ). For annealing, unmodified and all modified AS1411 aptamers were dissolved in potassium phosphate (PBK), heated at $90^{\circ} \mathrm{C}$ for 5 minutes, and allowed at room temperature prior to use. The Oligonucleotides were characterized by LC ESI-MS, and their purity assessed by HPLC and capillary gel electrophoresis (CGE).

2.3. Cell Culture. The cells, C6 (rat glioma cell line), HeLa (human cervix cancer cells), and CHO cells (chinese hamster ovary cell line), were maintained in DMEM (Gibco, Grand Island, NY) supplemented with $10 \%$ fetal bovine serum (FBS, Invitrogen, Grand Island, NY), $10 \mathrm{U} / \mathrm{mL}$ penicillin (Invitrogen, Grand Island, NY), and $10 \mu \mathrm{g} / \mathrm{mL}$ streptomycin in a $5 \% \mathrm{CO}_{2}$-humidified chamber at $37^{\circ} \mathrm{C}$. The cells were cultured in a multiwell chamber on slides overnight or for two days till they reached about $50 \%-80 \%$ confluence. After the cells reached a confluence of $90 \%-100 \%$, the media were aspirated from the cells with transfer pipettes and washed with PBS ( $1 \times$ Phosphate Buffered Saline) briefly. After trypsinization, the cells were collected in standard culture media and $1 / 5$ of the cells were centrifuged at $1000 \mathrm{rpm}$ for 5 minutes and transferred into T75 flask with $10 \mathrm{~mL}$ of media.

2.4. Protein Assay. To normalize the fluorescence signals of forty-seven Cy3-(5-BzdU)-modified AS1411 compounds, the cells treated with each compound were collected in $120 \mu \mathrm{L}$ PBS buffer after trypsinization, followed by BCA protein assay (Thermo Fisher Scientific Inc. Waltham, MA). The collected cells were moved into 96-microplate wells and treated with a mixture of reagent $\mathrm{A}$ and $\mathrm{B}(1: 50)$, and then incubated at $37^{\circ} \mathrm{C}$ for 30 minutes. After the biuret reaction, the absorbance, at or near $562 \mathrm{~nm}$ on the reader, was measured on a plate. 


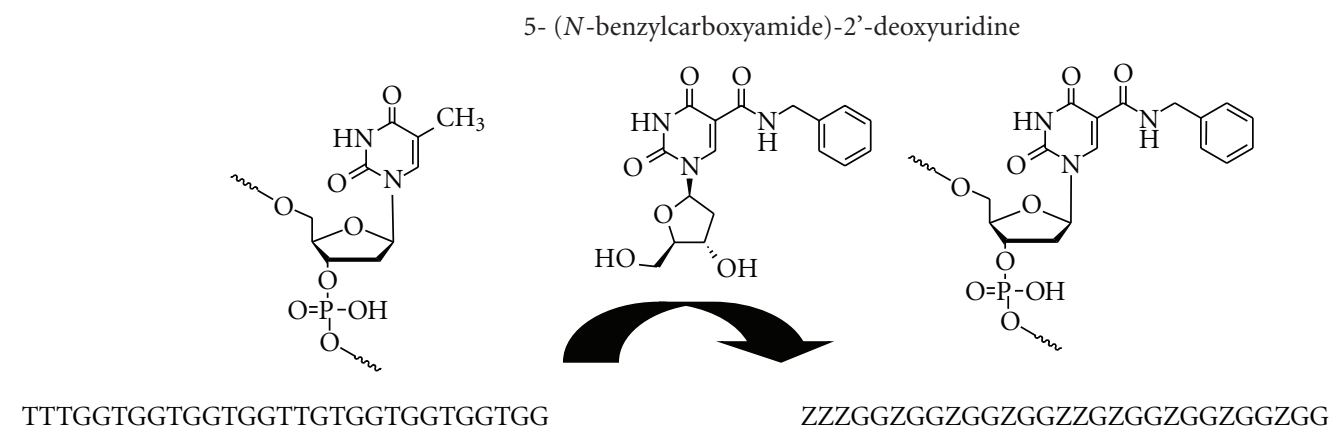

AS1411

FIGURE 1: Schematic diagram of the synthesis of the nucleolin aptamer containing 5-( $N$-benzylcarboxyamide)-2' -deoxyuridine. $Z$ indicates where the thymidines in AS1411 oligonucleotides were substituted with 5-( $N$-benzylcarboxyamide)-2' -deoxyuridine.

2.5. Fluorescence Intensity. The fluorescence intensities of forty-seven Cy3-(5-BzdU)-modified AS1411 compounds were quantified to evaluate the targeting efficiency in the C6 cells using the Varioskan Flash spectral scanning multimode reader (Thermo Fisher Scientific Inc. Waltham, MA; excitation: $535 \mathrm{~nm}$, scanning wavelength: $570 \mathrm{~nm}$ with a band width: $12 \mathrm{~nm}$ ). The C6 cells were seeded at a $1 \times 10^{5}$ cell density onto a MagnetoFACTION 24 plate (Chemicell, $\mathrm{GmbH}$, Germany) and placed in a $5 \% \mathrm{CO}_{2}$-humidified chamber. After 24 hours, the seeded cells were incubated at $4^{\circ} \mathrm{C}$ to decrease nonspecific binding over 30 minutes and rinsed with PBS $(1 \times)$, then replaced with $200 \mu \mathrm{L}$ of Tris buffer and then each of 47 different compounds (20 nM) treated. After 30 minutes at $4^{\circ} \mathrm{C}$, the seeded cells were washed two times for 10 minutes each at RT with shaking incubation $(30 \mathrm{rpm})$ and then trypsinized to detach the cells from the surface of the plate. The cells were then collected by PBS $(1 \times)$ $(120 \mu \mathrm{L})$ and transferred into a 96-well plate (Chemicell, $\mathrm{GmbH}$, Germany) for measurement of the fluorescence intensity $(100 \mu \mathrm{L})$. The data is presented as means $\pm \mathrm{SD}$ calculated from quadruple wells.

2.6. Confocal Laser Microscopy Assay. Confocal microscopy imaging with a laser scanning microscope (Carl Zeiss, Inc., Weimer, Germany; HFT 405/488 nm, DAPI imaging: 420480 nm, Cy3-labeled compounds: 488/543) was performed. The cells were seeded at a $1 \times 10^{5}$ density onto a $12 \mathrm{~mm}$ sterile coverslip in a 24 -well plate. After 24 hours, the cells were incubated with the Cy3-(5-BzdU)-modified AS1411 compounds $(20 \mathrm{nM})$ and studied after additional staining procedures for 30 minutes at $4^{\circ} \mathrm{C}$. To remove the unbound conjugates, the cells were washed three times over 10 minutes using shaking incubation $(30 \mathrm{rpm})$ in PBS $(1 \times)$ and fixed with $3.7 \%$ formaldehyde solution (Sigma, Saint Louis, MO) that was added to $200 \mu \mathrm{L}$ of the cells and incubated with shaking incubation $(20 \mathrm{rpm})$ each for 20 minutes. After the cells were washed three times with PBS, and 10 minutes of shaking incubation, nuclear staining was performed with a $4^{\prime}$,6-diamidino-2-phenylindole dihydrochloride (DAPI) using a mounting solution (Vector Laboratories, Inc., Burlingame, CA). The fixed cells were placed onto a coverslip with $10 \mu \mathrm{L}$ of mountain solution. The confocal images were acquired at low magnification $(200 \times)$.

2.7. MTT Assay. C6 cells were seeded onto 24-well plate at the density of $2 \times 10^{5}$ cell/well for 1 day and treated and incubated with $4 \mu \mathrm{M}$ of each compounds including numbers 12, 26, 29, and 41, the mutant, and Cy3-AS1411 for 1 day. $2 \mathrm{mg} / \mathrm{mL}$ of 3-(4,5-dimethythazolz-yl)-2,5-diphenyl tetrazolium bromide (MTT) solution was added to each well $(50 \mu \mathrm{L} /$ well $)$ and incubated for 4 hours at $37^{\circ} \mathrm{C}$. After aspiration, $500 \mu \mathrm{L}$ of DMSO was added into each well and incubated for 10 minutes at $37^{\circ} \mathrm{C}$. The resuspension was read at $540 \mathrm{~nm}$ by microreader (Tecan Spectra, Wetzlar, Germany). Antiproliferation ratio was calculated by the following formula: antiproliferation ratio $(\%)=\left(1-\mathrm{A}_{540}\right.$ of treated group $) /\left(A_{540}\right.$ of control group $) \times 100 \%$. All experiments were performed three times independently.

2.8. Statistical Analysis. The fold ratio of fluorescence activity for the 47 different compounds of Cy3-(5-BzdU)-modifiedAS1411 and the mutant AS1411 was normalized to the fluorescence signals of Cy3-AS1411. The $P$-values were calculated using the Student's $t$-test.

\section{Results and Analysis}

Forty-seven different compounds of Cy3-(5-BzdU)modified-AS1411 were designed and synthesized (Table 1). The AS1411 oligonucleotides incorporated with 5-BzdU and were labeled with $\mathrm{Cy} 3$ and prepared according to previously published procedure [20]. One to twelve thymidines in the AS1411 oligonucleotides were randomly replaced with Cy3-labeled 5-BzdU (Figure 1). Forty-seven Cy3-(5-BzdU)modified oligonucleotides, Table 1 , were synthesized on an automated solid phase DNA synthesizer. A $0.1 \mathrm{M}$ solution of phosphoramidite in anhydrous acetonitrile was used for the synthesis. The overall coupling efficiency of the 5- $(\mathrm{N}-$ benzylcarboxyamide)-2'-deoxyuridine-phosphoramidite was $>97 \%$. All of the oligonucleotides were characterized by LC ESI-MS and the purity was assessed by HPLC and capillary electrophoresis (Table 1). 
TABLE 1: A list of AS1411 compounds containing 5-(N-benzylcarboxyamide)-2'-deoxyuridine.

\begin{tabular}{|c|c|c|c|c|c|}
\hline Comp. No. & Sequence $\left(5^{\prime} \rightarrow 3^{\prime}\right)$ & Calculated Mass & Observed Mass & Fold ratio & $P$-value \\
\hline 1 & Cy3-labeled-ZTTGGTGGTGGTGGTTGTGGTGGTGGTGG & 9811.71 & 9812.32 & 1.12 & .59 \\
\hline 2 & Cy3-labeled-TZTGGTGGTGGTGGTTGTGGTGGTGGTGG & 9811.71 & 9811.72 & 1.04 & .58 \\
\hline 3 & Cy3-labeled-TTZGGTGGTGGTGGTTGTGGTGGTGGTGG & 9811.71 & 9811.92 & 1.07 & .66 \\
\hline 4 & Cy3-labeled-TTTGGZGGTGGTGGTTGTGGTGGTGGTGG & 9811.71 & 9812.27 & 1.62 & .06 \\
\hline 5 & Сy3- labeled-TTTGGTGGZGGTGGTTGTGGTGGTGGTGG & 9811.71 & 9811.83 & 1.27 & .19 \\
\hline 6 & Cy3- labeled-TTTGGTGGTGGZGGTTGTGGTGGTGGTGG & 9811.71 & 9812.38 & 1.94 & .07 \\
\hline 7 & Сy3- labeled-TTTGGTGGTGGTGGZTGTGGTGGTGGTGG & 9811.71 & 9812.18 & 0.62 & .01 \\
\hline 8 & Сy3- labeled-TTTGGTGGTGGTGGTZGTGGTGGTGGTGG & 9811.71 & 9812.22 & 0.97 & .74 \\
\hline 9 & Cy3- labeled-TTTGGTGGTGGTGGTTGZGGTGGTGGTGG & 9811.71 & 9812.01 & 0.96 & .86 \\
\hline 10 & Cy3- labeled-TTTGGTGGTGGTGGTTGTGGZGGTGGTGG & 9811.71 & 9812.1 & 0.6 & .02 \\
\hline 11 & Сy3- labeled-TTTGGTGGTGGTGGTTGTGGTGGZGGTGG & 9811.71 & 9812.69 & 1.2 & .39 \\
\hline 12 & Сy3- labeled-TTTGGTGGTGGTGGTTGTGGTGGTGGZGG & 9811.71 & 9811.78 & 2.44 & ** \\
\hline 13 & Сy3- labeled-TZZGGTGGTGGTGGTTGTGGTGGTGGTGG & 9930.82 & 9931.4 & 0.81 & .11 \\
\hline 14 & Сy3- labeled-ZZZGGTGGTGGTGGTTGTGGTGGTGGTGG & 9930.82 & 9931.24 & 1.04 & .79 \\
\hline 15 & Cy3- labeled-TTTGGTGGTGGTGGTTGTGGTGGZGGZGG & 9930.82 & 9931.02 & 0.89 & .56 \\
\hline 16 & Cy3- labeled-TTTGGTGGTGGTGGTTGTGGZGGTGGZGG & 9930.82 & 9931.1 & 0.86 & .02 \\
\hline 17 & Cy3- labeled-TTTGGTGGTGGTGGTTGZGGTGGTGGZGG & 9930.82 & 9931.81 & 0.95 & .8 \\
\hline 18 & Cy3- labeled-TTTGGTGGTGGTGGTZGTGGTGGTGGZGG & 9930.82 & 9930.93 & 1.07 & .83 \\
\hline 19 & Сy3- labeled-TTTGGTGGTGGTGGZTGTGGTGGTGGZGG & 9930.82 & ${ }^{*} \mathrm{~N} / \mathrm{A}$ & 0.65 & .14 \\
\hline 20 & Сy3- labeled-TTTGGTGGTGGZGGTTGTGGTGGTGGZGG & 9930.82 & N/A & 0.79 & ** \\
\hline 21 & Сy3- labeled-TTTGGTGGZGGTGGTTGTGGTGGTGGZGG & 9930.82 & N/A & 1.57 & .17 \\
\hline 22 & Cy3- labeled-TTTGGZGGTGGTGGTTGTGGTGGTGGZGG & 9930.82 & 9931.81 & 1.39 & .16 \\
\hline 23 & Сy3- labeled-TTZGGTGGTGGTGGTTGTGGTGGTGGZGG & 9930.82 & N/A & 0.94 & .51 \\
\hline 24 & Cy3- labeled-TZTGGTGGTGGTGGTTGTGGTGGTGGZGG & 9930.82 & N/A & 0.7 & 03 \\
\hline 25 & Cy3- labeled-ZTTGGTGGTGGTGGTTGTGGTGGTGGZGG & 9930.82 & N/A & 0.65 & $* *$ \\
\hline 26 & Сy3- labeled-TTTGGTGGTGGTGGZZGTGGTGGTGGZGG & 10049.93 & N/A & 0.09 & ** \\
\hline 27 & Сy3- labeled-TZZGGTGGTGGTGGTTGTGGTGGTGGZGG & 10049.93 & N/A & 0.06 & ** \\
\hline 28 & Сy3- labeled-ZZTGGTGGTGGTGGTTGTGGTGGTGGZGG & 10049.93 & 10051.4 & 1.42 & .02 \\
\hline 29 & Cy3- labeled-TTTGGTGGTGGTGGZZGTGGTGGTGGTGG & 9930.82 & N/A & 1.62 & .02 \\
\hline 30 & Сy3- labeled-TTTGGTGGTGGTGGZZGZGGTGGTGGTGG & 10049.93 & N/A & 1.04 & 27 \\
\hline 31 & Cy3- labeled-TTTGGTGGTGGTGGZZGTGGZGGTGGTGG & 10049.93 & N/A & 1.37 & .1 \\
\hline 32 & Cy3- labeled-TTTGGTGGTGGTGGZZGTGGTGGZGGTGG & 10049.93 & N/A & 1.32 & .05 \\
\hline 33 & Сy3- labeled-TTTGGTGGTGGZGGZZGTGGTGGTGGTGG & 10049.93 & N/A & 1.19 & .41 \\
\hline 34 & Сy3- labeled-TTTGGTGGZGGTGGZZGTGGTGGTGGTGG & 10049.93 & N/A & 1.03 & .12 \\
\hline 35 & Cy3- labeled-TTTGGZGGTGGTGGZZGTGGTGGTGGTGG & 10049.93 & 10050.99 & 1.2 & $* *$ \\
\hline 36 & Сy3- labeled-TTZGGTGGTGGTGGZZGTGGTGGTGGTGG & 10049.93 & N/A & 1.11 & 26 \\
\hline 37 & Су3- labeled-TZTGGTGGTGGTGGZZGTGGTGGTGGTGG & 10049.93 & N/A & 1.43 & .06 \\
\hline 38 & Cy3- labeled-ZTTGGTGGTGGTGGZZGTGGTGGTGGTGG & 10049.93 & N/A & 1.17 & .17 \\
\hline 39 & Cy3- labeled-TZZGGTGGTGGTGGZZGTGGTGGTGGTGG & 10169.04 & N/A & 1.64 & .01 \\
\hline 40 & Сy3- labeled-ZZTGGTGGTGGTGGZZGTGGTGGTGGTGG & 10169.04 & N/A & 0.8 & .01 \\
\hline 41 & Су3- labeled-ZTZGGTGGTGGTGGZZGTGGTGGTGGTGG & 10169.04 & N/A & 1.9 & ** \\
\hline 42 & Сy3- labeled-ZZZGGTGGTGGTGGZZGTGGTGGTGGTGG & 10288.15 & 10288.41 & 1.21 & .03 \\
\hline 43 & Cy3- labeled-TTTGGTGGTGGZGGTTGZGGTGGTGGTGG & 9930.82 & N/A & 0.89 & .01 \\
\hline 44 & Cy3- labeled-TTTGGTGGZGGTGGTTGTGGZGGTGGTGG & 9930.82 & N/A & 1.04 & .77 \\
\hline 45 & Cy3- labeled-TTTGGZGGTGGTGGTTGTGGTGGZGGTGG & 9930.82 & N/A & 1.17 & .14 \\
\hline 46 & Су3- labeled-TTTGGTGGZGGZGGTTGZGGZGGZGGTGG & 10288.15 & N/A & 1.01 & 94 \\
\hline 47 & Сy3- labeled-TTTGGZGGZGGZGGTTGZGGZGGTGGZGG & 10407.26 & N/A & 1.11 & .08 \\
\hline AS & Сy3- labeled-TTTGGTGGTGGTGGTTGTGGTGGTGGTGG & 9692.60 & 9693.85 & 1 & \\
\hline Mt & Су3-labeled-ТTТССТССТССТССТТСТССТССТССТСС & 9012.09 & 9012.7 & 0.26 & ** \\
\hline
\end{tabular}

Cy3-(5-BzdU)-modified-AS1411 derivatives contained 5-(N-benzylcarboxyamide)-2'-deoxyuridine in Z. AS indicates the original sequence of AS1411 and Mt indicates the mutant form of AS1411. ${ }^{* *}$, The value of observed mass for 49 compounds was randomly measured and N/A indicates no value available. 


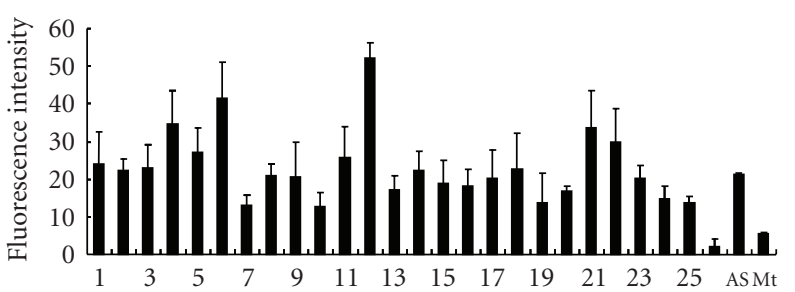

(a)

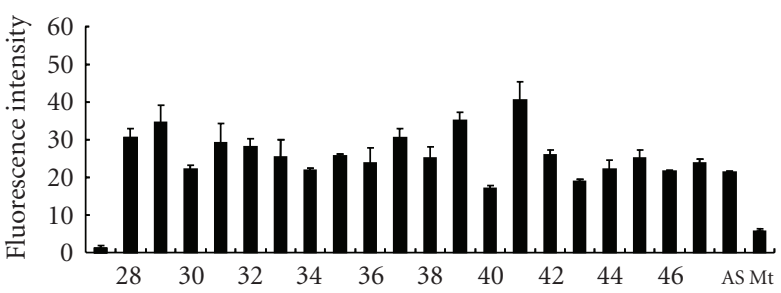

(b)

FIGURE 2: Fluorescence analysis of Cy3-(5-BzdU)-modified-AS1411 compounds targeting C6 cells. The fluorescence of the 47 different Cy3(5-BzdU)-modified-AS1411 compounds that were bound and targeted the nucleolin protein in the C6 cells was quantified. The X-axis indicates numbers of compounds. AS represents the Cy3-labeled AS1411 and Mt the mutant form of the original AS1411 labeled with Cy3. These data are presented as the means \pm SD calculated from quadruple wells. All fluorescence data were obtained at an excitation of $535 \mathrm{~nm}$ and emission of $570 \mathrm{~nm}$.

To determine the targeting efficiency of the cancers, using 47 different compounds of Cy3-(5-BzdU)-modifiedAS1411, the C6 cells (a rat glioma cell line) were first seeded at a $1 \times 10^{5}$ cell density onto 24 -well plates. After 1 day of growth, the seeded cells were incubated with $20 \mathrm{nM}$ of Cy3-labeled chemically unmodified AS1411 (designated as Cy3-AS1411) or $20 \mathrm{nM}$ of each of the 47 different Cy3-(5-BzdU)-modified-AS1411 compounds at $4^{\circ} \mathrm{C}$ for 30 minutes, to prevent nonspecific binding, and then rinsed with PBS $(\times 1)$ to remove the unbound Cy3-(5-BzdU)modified-AS1411 among each of the compounds in the cells $[21,22]$. The fluorescence intensities of the Cy3-(5-BzdU)modified-AS1411 compounds, targeting the nucleolin proteins expressed in the cellular membrane of the C6 cells, were quantified and normalized by units of the cells measured by the Bradford protein assay. Comparison of the fluorescent intensity of the Cy3-AS1411 with excitation at $488 \mathrm{~nm}$ and emission at $543 \mathrm{~nm}$ showed that 30 out of the 47 different compounds showed either a slight increase or a significantly greater fluorescent activity in the C6 cells (Figure 2). In addition, 17 out of the 47 different compounds showed reduced fluorescence signals compared to the Cy3-AS1411. Furthermore, among the 17 compounds, numbers 26 and 27 showed much lower fluorescence activity in the targeted C6 cells than the mutant AS1411, which had complete loss of function of the AS1411.

The fold ratio for the fluorescence signals of the 47 different compounds of Cy3-(5-BzdU)-modified-AS1411 was normalized to that of the Cy3-AS1411 and showed that seven different compounds, numbers 4, 6, 12, 21, 29, 39, and 41 , had about a 1.5 -fold or more binding affinity for the C6 cells (Table 1). In particular, number 12 compound had approximately a 2.5 -fold higher fluorescent signal than the Cy3-AS1411. Statistical analysis using the Student $t$ test demonstrated that a $P$-value with higher than .05 was found in 18 different compounds among the Cy3(5-BzdU)-modified-AS1411 including numbers 12, 29, 39, and 41 . These results imply that 5-BzdU modification of the numbers $12,29,39$, and 41 compounds significantly increased the targeting affinity for the C6 cells.

To further validate the increased binding affinity of Cy3(5-BzdU)-modified-AS1411 by confocal microscopy analysis, compounds numbers 12,29 , and 41 were incubated and visualized in C6 cells with control compounds, number 26 (significantly lose the targeting function of AS1411), Cy3AS1411 and a mutant of Cy3-AS1411 (negative control). Twenty $20 \mathrm{nM}$ of each compound was targeted in the C6 cells. Comparison of the phase-contrast image and the nuclear DAPI staining revealed that numbers 12, 29, and 41, and Cy3-AS1411 were extensively bound to the plasma membrane of the C6 cells while the mutant Cy3-AS1411 and number 26 compound were not clearly visualized in the C6 cells (Figure 3 ). The targeting affinity to C6 cells, shown in Figure 1, demonstrated that numbers 12,29 , and 41 had better targeting affinity than did Cy3-AS1411. The number 12 compound showed the highest fluorescent brightness in C6 cells.

To test functional activity of the compounds numbers 12,29 , and 41 in other cancer cells, we first extended cancer targeting assay by selecting another cancer cells, HeLa (human cervix cancer cell line), and a normal healthy cell line, $\mathrm{CHO}$ (chinese hamster ovary cell line). Similar results with C6 cell quantitative fluorescence intensity showed that numbers 12, 29, and 41 had the higher binding affinity for the HeLa cells than the Cy3-AS1411, while the mutant and the compound number 26 had no significant fluorescent signal in HeLa cells (Figure 4(a)). Especially, the number 12 compound had approximately a 2.3-fold higher fluorescent activity in HeLa cells than the Cy3-AS1411. However, in $\mathrm{CHO}$ cells, the compounds including numbers 12, 26, 29, and 41, the mutant, and Cy3-AS1411 showed undetectable fluorescence intensity (Figure 4(a)). There was no significant difference in binding affinity to $\mathrm{CHO}$ cells compared with the mutant. Confocal microscopy analysis validated that the compounds numbers 12, 29, and 41 had extensively and better binding affinity to the plasma membrane of the HeLa cells than the Cy3-AS1411, while the mutant and number 26 compound were not significantly visualized in the HeLa cells (Figure 4(b)). As expected, the compounds including numbers 12, 26, 29, and 41, the mutant, and Cy3-AS1411 were not clearly visualized in $\mathrm{CHO}$ cells (Figure 4(c)). To test another functional activity of the chemically modified nucleolin aptamer, we performed cell proliferation test by MTT assay due to the fact that nucleolin aptamer has antiproliferative effects by specifically binding to the nucleolin transmembrane protein in cancer cells $[7,19] .4 \mu \mathrm{M}$ of 
AS1411

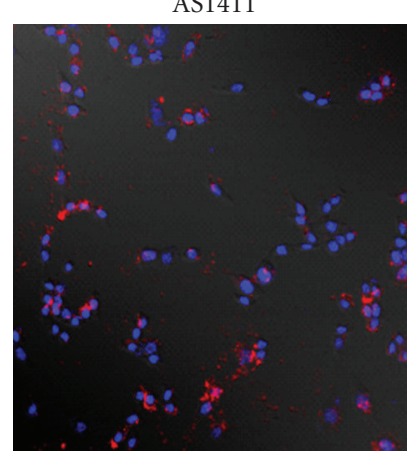

(a)

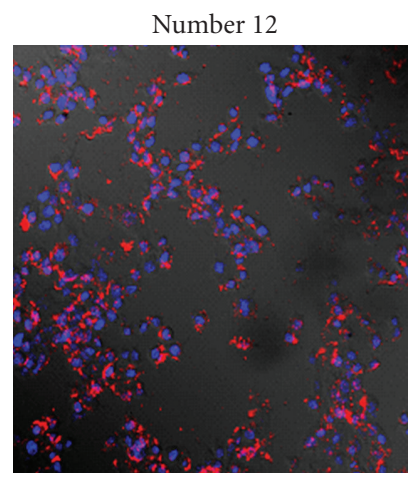

(d)

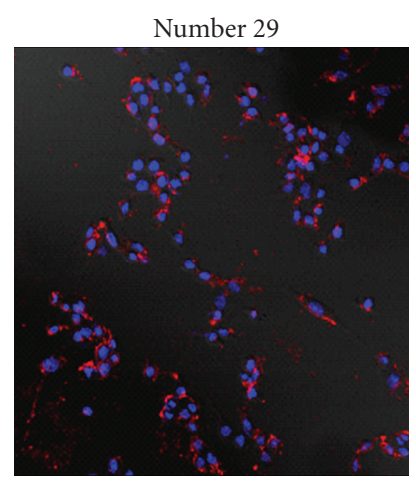

(b)

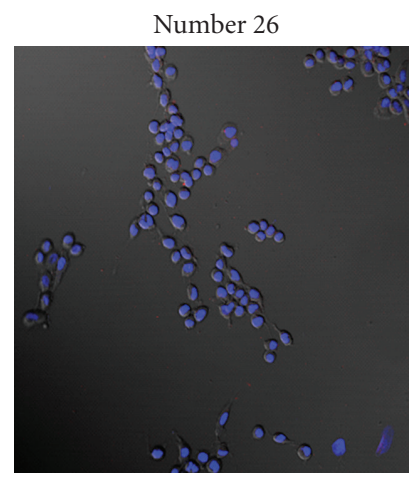

(e)

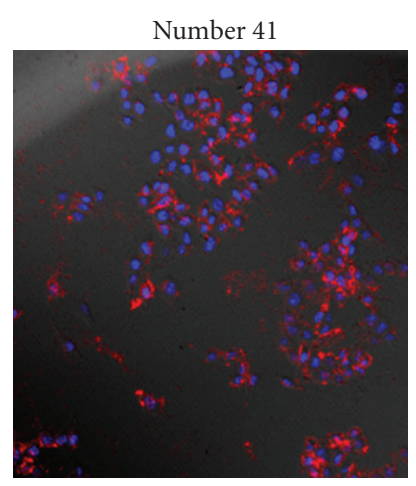

(c)

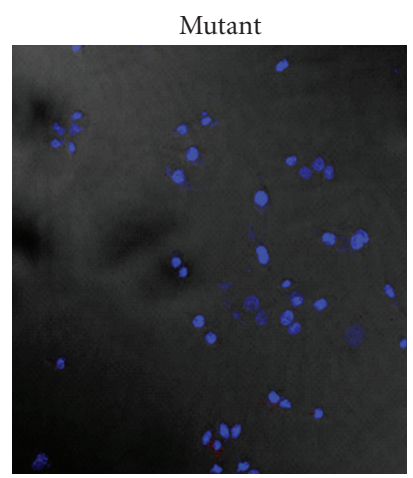

(f)

FIgURE 3: Confocal microscopy imaging of the Cy3-(5-BzdU)-modified-AS1411 targeting the C6 cells. numbers 29, 41, 12, and 26, Cy3AS1411, and the mutant form of AS1411 labeled with Cy3 were visualized in the C6 cells. The confocal images were magnified to 200x. The nucleus was stained by DAPI (emission: $460 \mathrm{~nm}$, blue color) and fluorescent imaging of the targeting of the C6 cells was visualized by a red color. Fluorescence images were acquired at an excitation of $535 \mathrm{~nm}$ and emission of $570 \mathrm{~nm}$.

each compound, numbers $12,26,29$, and 41 , the mutant, and Cy3-AS1411 were added directly to C6 cells and incubated for 1 day (Figure 4(d)). The compounds numbers 41 and 12 showed significantly higher antiproliferative effect than the Cy3-AS1411, representing 55\% and $65 \%$ of cell viability. Meanwhile, cell proliferation effect of the compound number $29(75 \%)$ did not show any significant difference from the Cy3-AS1411 (78\%).

We synthesized various compounds of Cy3-(5-BzdU)modified-AS1411 with single or multiple 5-BzdUs to increase their binding affinity to nucleolin proteins in the cell membranes of cancer cells. The quantification of fluorescent signals demonstrated that a variety of chemically modified AS1411 compounds using 5-BzdU had varied binding affinity to cancer cells. The number and position of substituents in the AS1411 nucleotides were compared with the original sequences of AS1411. Our statistical analysis and confocal microscopy imaging showed that at least three compounds, numbers 12, 29, and 41 out of 47 different Cy3-(5BzdU)-modified-AS1411, resulted in a significant increase in targeting the $\mathrm{C} 6$ cells. To assess whether the number and position of the 5 -( $N$-benzylcarboxyamide)- $2^{\prime}$-deoxyuridine incorporated into AS1411 had the influence of targeting and binding the $\mathrm{C} 6$ cells, the chemically modified sequences of the 47 different compounds of Cy3-(5-BzdU)-modifiedAS1411 were compared with regard to their fluorescent activity in targeting of the C6 cells. There are 12 thymidine nucleotides in the AS1411 sequence that can be substituted with 5-BzdU. A single substitution of a thymidine located at the 4 th to 6 th, 11 th, and 12 th position from the $5^{\prime}$ terminal site of AS1411 significantly increased the targeting affinity for the C6 cells (Table 1). However, replacement of the remaining thymidines did not result in a significant difference in the binding affinity for the cancer cells. Two modified nucleotides, with one fixed incorporation of 5 -BzdU at the 12th thymidine, resulted in the highest binding affinity to the cancer cells and showed increased targeting affinity with the other modifications only at the 4th and 5th thymidine. In addition, most of the double incorporated 5-BzdU at the 7th and 8th thymidine, in the AS1411 compound, produced either a slight improvement or a significant improvement in the binding affinity for the $\mathrm{C} 6$ cells. Of note was that number 26, the simultaneous substitution of the 7th, 8 th, and 12th thymidine, of AS1411 with 5-BzdU, resulted in complete loss of the binding affinity for the C6 cells (Figure 5). Other random heavy modification of AS1411 did not result in a significant increase in the binding affinity for the C6 cells. These findings imply that chemical modification of 


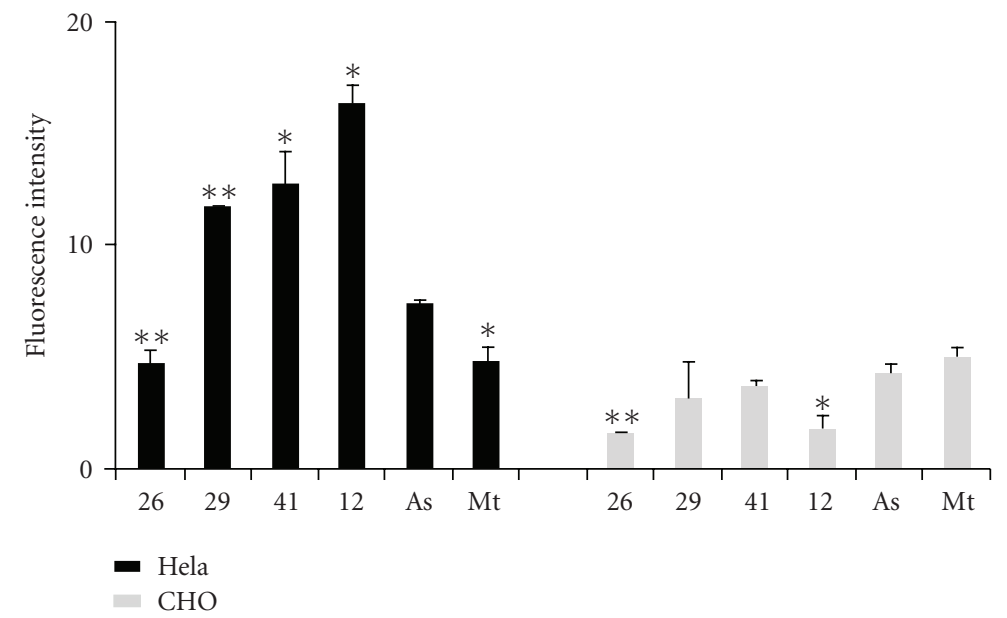

(a)

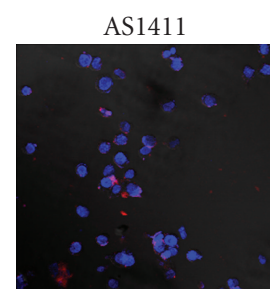

Number 12
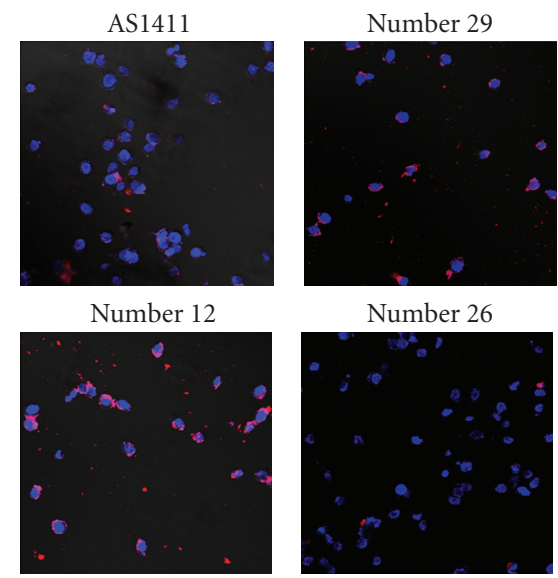

Number 26

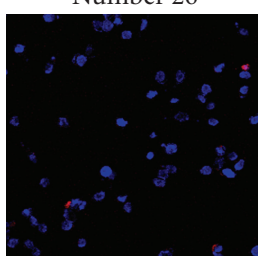

(b)

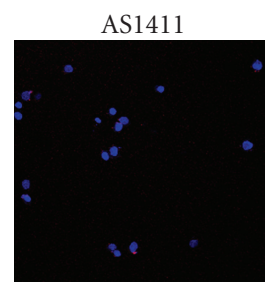

Number 12
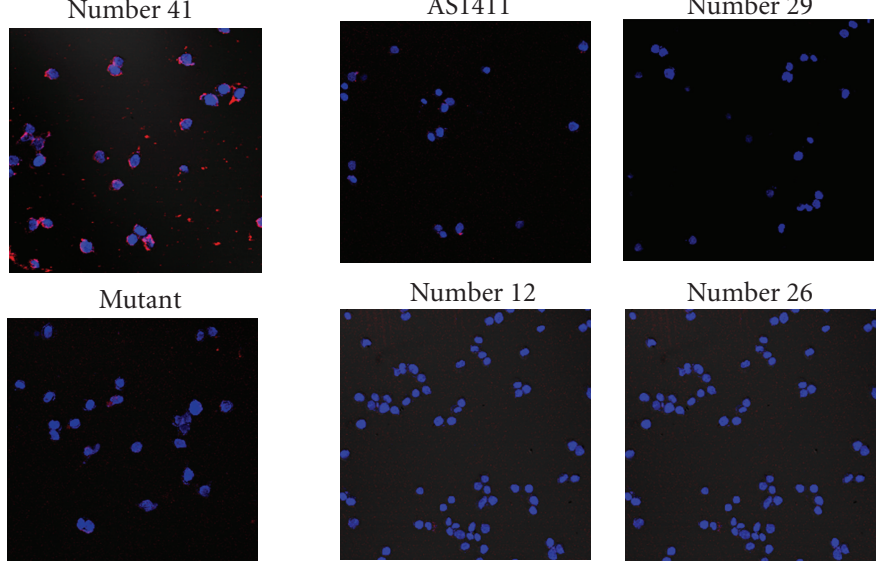

Number 26

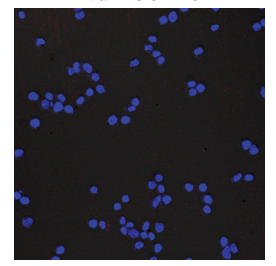

(c)

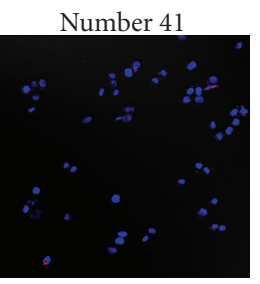

Mutant

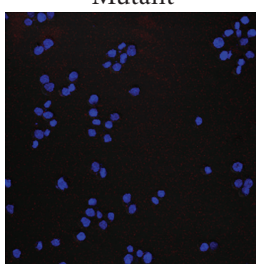

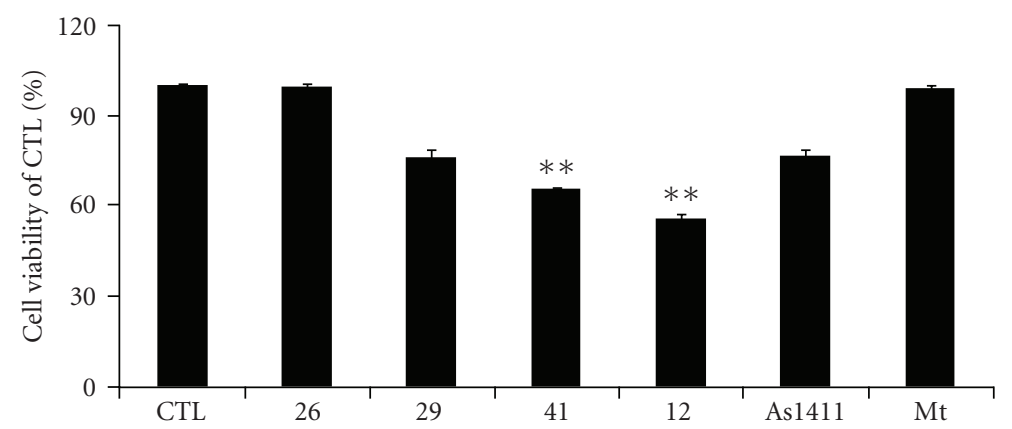

(d)

Figure 4: Fluorescence analysis of numbers 29, 41, 12, and 26, Cy3-AS1411, and the mutant form of AS1411 labeled with Cy3. (a) Quantitative fluorescence intensity in HeLa and CHO cells. Data are represented as means \pm standard error of means $\left({ }^{*} P<.05,{ }^{* *} P<.005\right.$ unpaired $t$-test). (b) Confocal microscopy imaging in HeLa cells. (c) Confocal microscopy imaging in CHO cells. (d) Antiproliferation effects were measured by MTT assay. $4 \mu \mathrm{M}$ of each compounds was treated at $2 \times 10^{5} \mathrm{C} 6$ cells per well. Data are represented as means \pm standard error of means ( ${ }^{* *} P<.005$ unpaired $t$-test).

thymidines at the central or $3^{\prime}$ terminal region of AS1411 with 5-BzdU forms a more stable G-quadruplex structure via hydrophobic cavities and enhances the potential binding affinity of AS1411 for cancer cells.
The results of this study highlight the fact that chemical modifications can directly applied to alter existing aptamers thereby increasing their binding affinity for targets without a significant increase in time or labor for the SELEX procedure. 


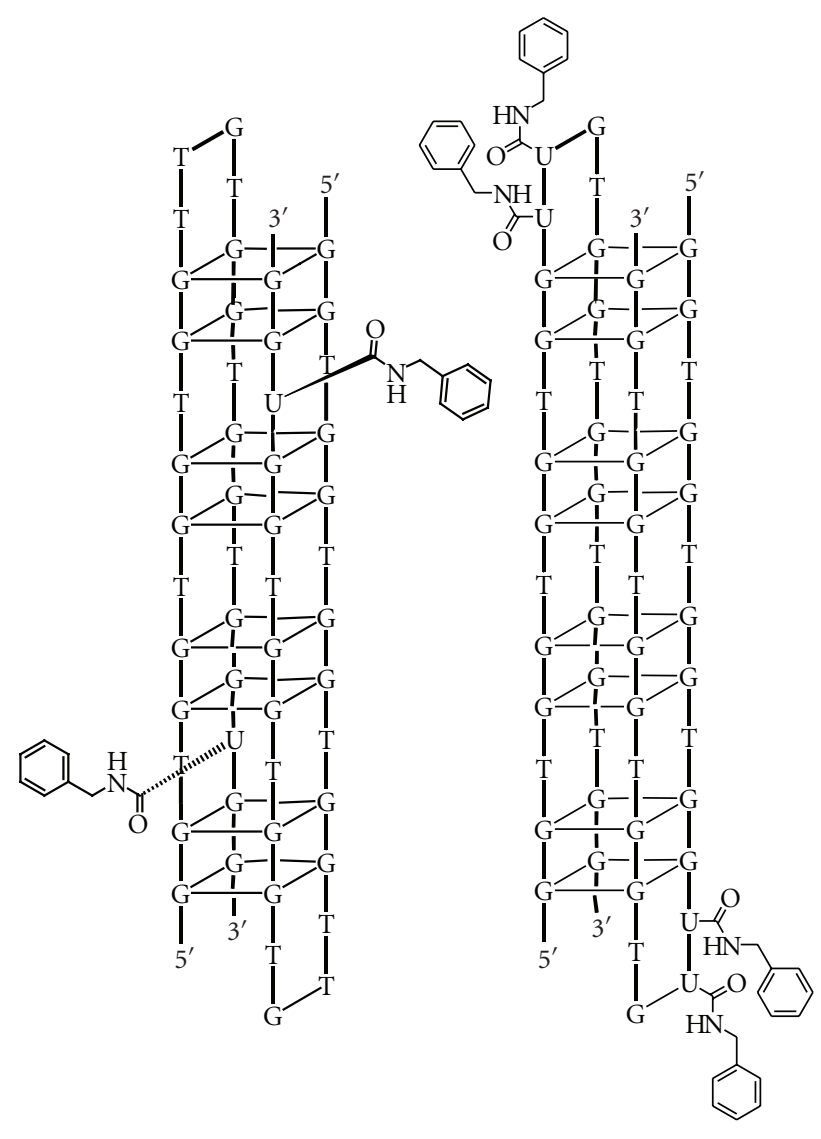

Number 12
Number 29

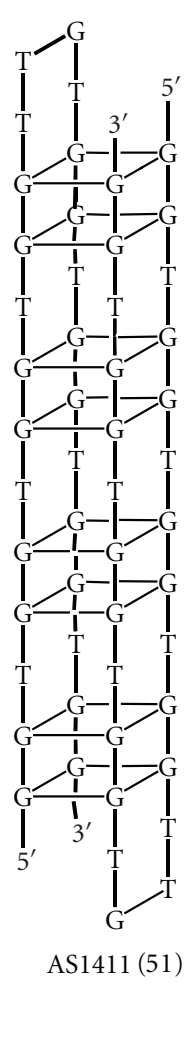

AS1411

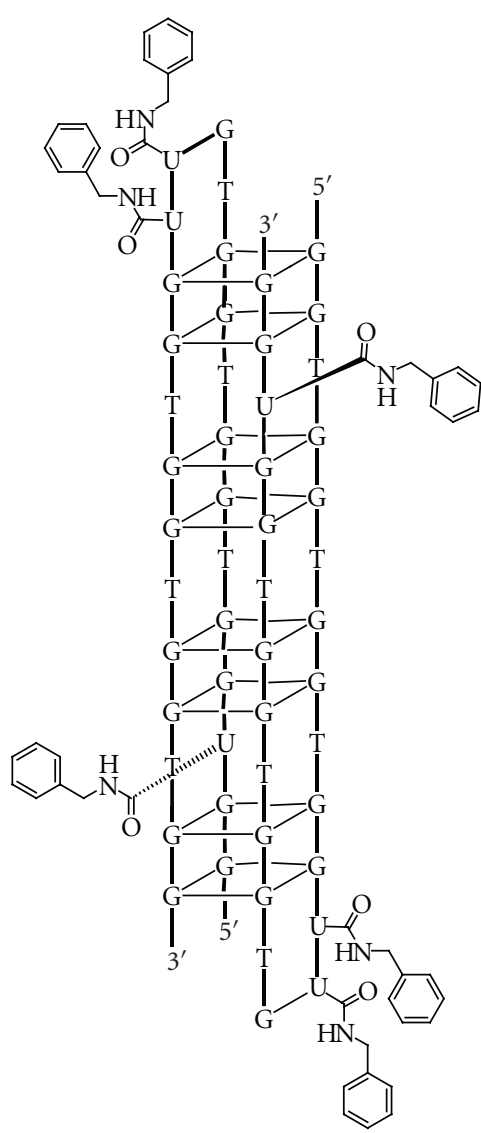

Number 26

FIGURE 5: Correlation between the structure and activity of the 5-BzdU-modified-AS1411. The position and structure of the chemical modification in numbers 12, 29, and 26 and the original sequence of AS1411 were drawn in G-quadruplex structure that normally formed by dimerization of AS1411 aptamers to bind to nucleolin protein.

Such chemically modified aptamers could be used as a valuable clinical tool for identifying serious cancer disease, in a very early stage, and evaluation of cancer therapy. However, further analysis including the study of diverse existing aptamers and their targets as well as study of resistance to enzymatic degradation, biostability in vivo, and optimization of the number and positioning of the 5-BzdU compounds in the sequence of the existing aptamers must be studied before in vivo application is considered for the detection and treatment of cancers.

\section{Conflict-of-Interest Disclosure}

The authors declare no competing interests.

\section{Acknowledgments}

The authors thank the Peptide Library Support Facility of POSTECH for the preparation of the oligonucleotides. This work was supported by National R\&D Program for Cancer Control of Ministry of Health \& Welfare (0820320), National Research Foundation of Korea (no. 20090084640), POSCO Strategy R\&D program (40003503.01), and a grant of the
Korea Healthcare technology R\&D Project, Ministry for Health, Welfare \& Family Affairs, South Korea (A085136).

\section{References}

[1] A. D. Ellington and J. W. Szostak, "In vitro selection of RNA molecules that bind specific ligands," Nature, vol. 346, no. 6287, pp. 818-822, 1990.

[2] C. Tuerk and L. Gold, "Systemic evolution of ligands by exponential enrichment: RNA ligands to bacteriophage T4 DNA polymerase," Science, vol. 249, no. 4968, pp. 505-510, 1990.

[3] B. E. Eaton, L. Gold, B. J. Hicke, et al., "Post-SELEX combinatorial optimization of aptamers," Bioorganic and Medicinal Chemistry, vol. 5, no. 6, pp. 1087-1096, 1997.

[4] N. Bardeesy and J. Pelletier, "Overlapping RNA and DNA binding domains of the wt1 tumor suppressor gene product," Nucleic Acids Research, vol. 26, no. 7, pp. 1784-1792, 1998.

[5] K. H. Choi, M. W. Park, S. Y. Lee, et al., "Intracellular expression of the T-cell factor-1 RNA aptamer as an intramer," Molecular Cancer Therapeutics, vol. 5, no. 9, pp. 2428-2434, 2006.

[6] J. Pas, E. Wyszko, K. Rolle, et al., "Analysis of structure and function of tenascin-C," International Journal of Biochemistry and Cell Biology, vol. 38, no. 9, pp. 1594-1602, 2006. 
[7] S. Christian, J. Pilch, M. E. Akerman, K. Porkka, P. Laakkonen, and E. Ruoslahti, "Nucleolin expressed at the cell surface is a marker of endothelial cells in angiogenic blood vessels," Journal of Cell Biology, vol. 163, no. 4, pp. 871-878, 2003.

[8] J. S. Rudge, J. Holash, D. Hylton, et al., "VEGF Trap complex formation measures production rates of VEGF, providing a biomarker for predicting efficacious angiogenic blockade," Proceedings of the National Academy of Sciences of the United States of America, vol. 104, no. 47, pp. 18363-18370, 2007.

[9] Z. Zhang and H. J. Schluesener, "Pigpen is a cellular binding protein of therapeutic oligonucleotides," Cytotherapy, vol. 7, no. 2, pp. 186-194, 2005.

[10] P. Mhawech-Fauceglia, S. Zhang, L. Terracciano, et al., "Prostate-specific membrane antigen (PSMA) protein expression in normal and neoplastic tissues and its sensitivity and specificity in prostate adenocarcinoma: an immunohistochemical study using mutiple tumour tissue microarray technique," Histopathology, vol. 50, no. 4, pp. 472-483, 2007.

[11] R. S. Herbst, "Review of epidermal growth factor receptor biology," International Journal of Radiation Oncology Biology Physics, vol. 59, no. 2, supplement, pp. 21-26, 2004.

[12] S. T. Crooke and C. F. Bennett, "Progress in antisense oligonucleotide therapeutics," Annual Review of Pharmacology and Toxicology, vol. 36, pp. 107-129, 1996.

[13] J. Micklefield, "Backbone modification of nucleic acids: synthesis, structure and therapeutic applications," Current Medicinal Chemistry, vol. 8, no. 10, pp. 1157-1179, 2001.

[14] P. E. Burmeister, S. D. Lewis, R. F. Silva, et al., "Direct in vitro selection of a 2'-O-methyl aptamer to VEGF," Chemistry and Biology, vol. 12, no. 1, pp. 25-33, 2005.

[15] S. M. Lato, N. D. S. Ozerova, K. He, Z. Sergueeva, B. R. Shaw, and D. H. Burke, "Boron-containing aptamers to ATP," Nucleic Acids Research, vol. 30, no. 6, pp. 1401-1407, 2002.

[16] Y. Kato, N. Minakawa, Y. Komatsu, et al., "New NTP analogs: the synthesis of $4^{\prime}$-thioUTP and 40-thioCTP and their utility for SELEX," Nucleic Acids Research, vol. 33, no. 9, pp. 29422951, 2005.

[17] B. E. Eaton, "The joys of in vitro selection: chemically dressing oligonucleotides to satiate protein targets," Current Opinion in Chemical Biology, vol. 1, no. 1, pp. 10-16, 1997.

[18] J. R. Heil, D. J. Schneider, D. T. Nieuwlandt, et al., US patent US 2007/0166741 A1, 2007.

[19] M. H. Ko, S. Kim, W. J. Kang, et al., "In vitro derby imaging of cancer biomarkers using quantum dots," Small, vol. 5, no. 10, pp. 1207-1212, 2009.

[20] J. D. Vaught, T. Dewey, and B. E. Eaton, "T7 RNA polymerase transcription with 5-position modified UTP derivatives," Journal of the American Chemical Society, vol. 126, no. 36, pp. 11231-11237, 2004.

[21] S. Dwarakanath, J. G. Bruno, A. Shastry, et al., "Quantum dot-antibody and aptamer conjugates shift fluorescence upon binding bacteria," Biochemical and Biophysical Research Communications, vol. 325, no. 3, pp. 739-743, 2004.

[22] N. Anikeeva, T. Lebedeva, A. R. Clapp, et al., "Quantum dot/peptide-MHC biosensors reveal strong CD8-dependent cooperation between self and viral antigens that augment the T cell response," Proceedings of the National Academy of Sciences of the United States of America, vol. 103, no. 45, pp. 16846-16851, 2006. 


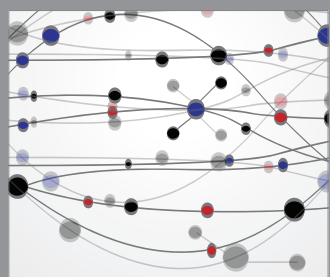

The Scientific World Journal
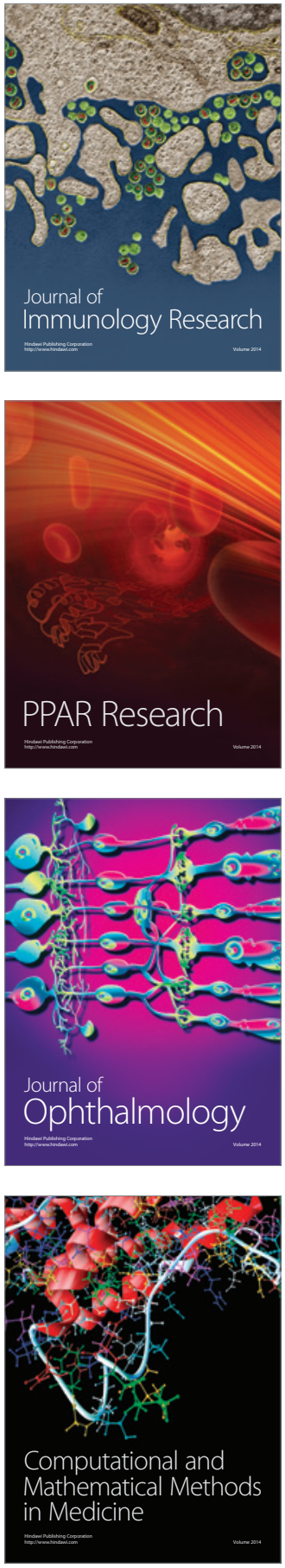

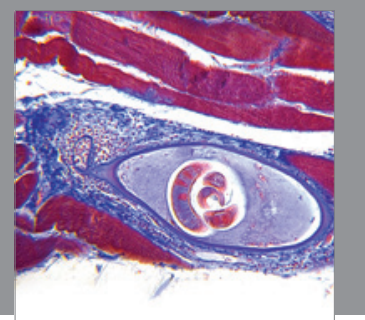

Gastroenterology

Research and Practice
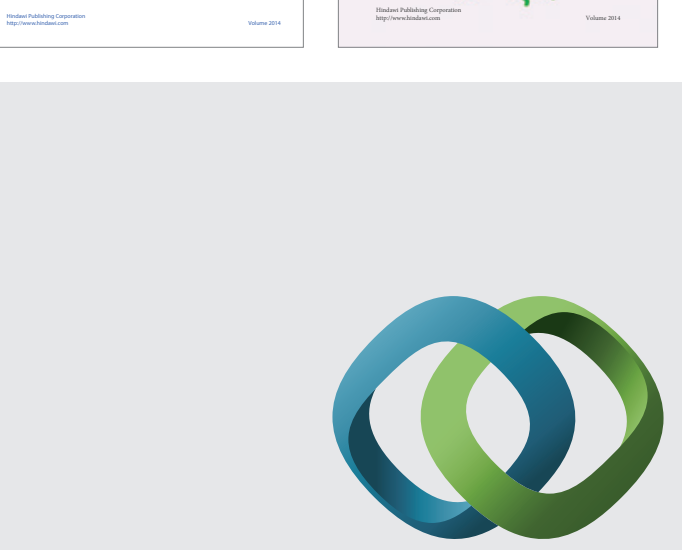

\section{Hindawi}

Submit your manuscripts at

http://www.hindawi.com
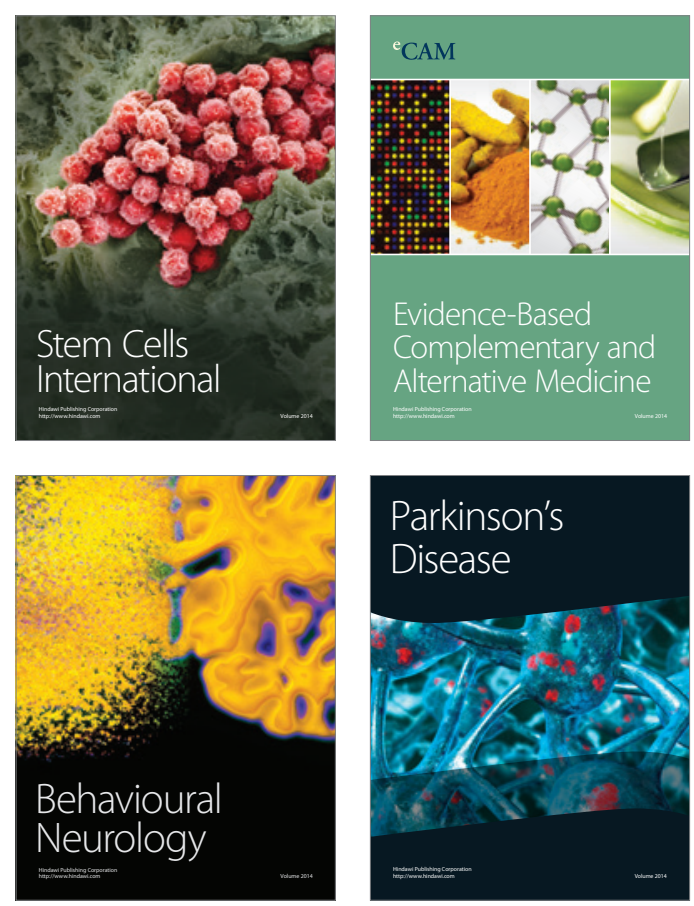

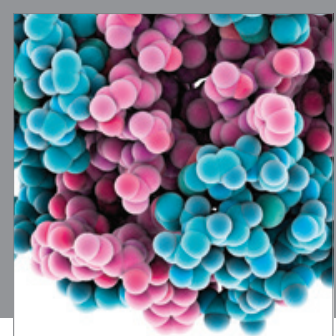

Journal of
Diabetes Research

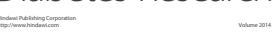

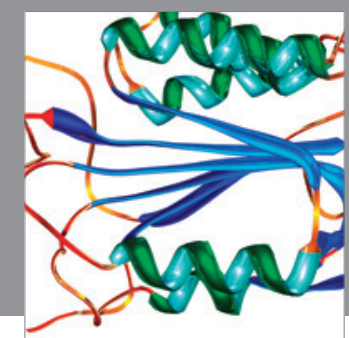

Disease Markers
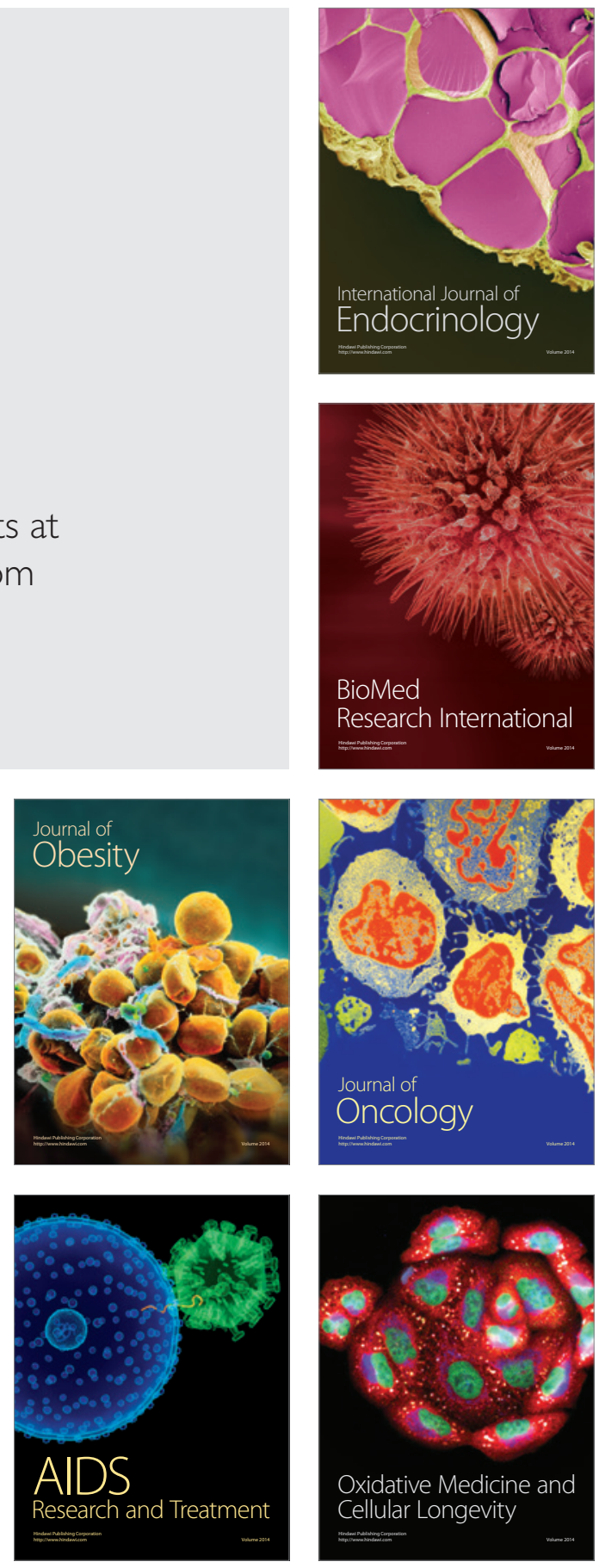